Original article

\title{
Dimensions of quality of life in the different stages of chronic kidney disease patients - A cross-sectional study
}

\author{
Maria Pauly $^{\mathrm{a}}$, Uday Venkat Mateti ${ }^{\mathrm{a}, *}$, Pradeep Shenoy ${ }^{\mathrm{b}}$, Neethu Saj ${ }^{\mathrm{a}}$, Malona Lilly Philip ${ }^{\mathrm{a}}$ \\ ${ }^{a}$ Department of Pharmacy Practice, NGSM Institute of Pharmaceutical Sciences, Nitte (Deemed to be University), Paneer, Deralakatte, Mangaluru, Karnataka, 575018, \\ India \\ ${ }^{\mathrm{b}}$ Department of Nephrology, KS Hegde Medical Academy, Justice K.S. Hegde Charitable Hospital, Nitte (Deemed to be University), Deralakatte, Mangaluru, Karnataka, \\ 575018, India
}

\section{A R T I C L E I N F O}

\section{Keywords:}

Chronic kidney disease

Quality of life

Risk factors

\begin{abstract}
A B S T R A C T
Background: Chronic Kidney Disease (CKD) is an emerging disease that causes morbidity, mortality and affects patient's quality of life (QoL). Objectives: To assess and compare dimensions of QoL in the different stages of CKD patients and also to identify the factors affecting QoL. Data and methods: A cross-sectional study was carried out for a period of 8 months in the Dept. of Nephrology. The inclusion criterion of the study is patients above 18 years age diagnosed with CKD stage 3-5 and patients undergoing maintenance haemodialysis. The patients were assessed for QoL using European-QoL-5-dimensional (EQ-QoL-5D) and visual analog scale (VAS) questionnaires. Results: Out of 210 patients, most of the patients were in the age group 51-65 years (43.33\%) and the mean age of study population was $52 \pm 16.04$. In the present study, most of the patients were males (79.04\%). The most common comorbidities were hypertension (90\%) and 51\% of diabetes mellitus (DM). The mean EQ-5D index scores of the CKD stage 3, 4, 5 and $5 \mathrm{D}$ patients were $0.77 \pm 0.09,0.67 \pm 0.10,0.62 \pm 0.12$ and $0.50 \pm 0.15$ and the mean VAS scores for these stages were 74.10 $\pm 7.68,66.52 \pm 10.90,66.45 \pm 8.80$ and $55.04 \pm 12.82$ respectively. Conclusion: The most commonly affected domains were usual activities (79\%), pain (76.20\%) and anxiety/depression (71.91\%). Factors such as age ( $>65 \mathrm{yrs),} \mathrm{BMI} \mathrm{(Underweight} \mathrm{and} \mathrm{Obese),}$ educational background (Illiterate), Unemployment, domiciliary status (Rural), number of medications ( $>11$ ) had significant association with EQ-5D index and VAS scores (p-0.000). It was found that QoL was impaired in stage 5D compared to other stages (p-0.000).
\end{abstract}

\section{Introduction}

The prevalence of Chronic Kidney Disease (CKD) is increasing worldwide and is a global problem due to the hasty increase in common risk factors such as hypertension (HTN) and diabetes mellitus (DM). ${ }^{1,2}$ In India, the prevalence of CKD is $17.2 \%$ and $6 \%$ in stage 3 and above. ${ }^{3}$ Mortality from cardiac disease is projected to be $8-10$ times more in CKD patients as compared to non-CKD patients. ${ }^{4}$ QoL is an important measure of how the disease affects patients' lives. CKD patients have decreased quality of life (QoL) compare to healthy controls. QoL is an important marker to assess the disease burden and can also be used to evaluate the treatment effectiveness and predict risk for adverse outcomes. ${ }^{5}$ A comprehensive study on factors influencing the QoL will render valuable perspicacity for the nephrologists to improve the QoL of patients. Nevertheless, the studies that assess the QoL and factors affecting CKD patients in developing countries are less. ${ }^{6}$ The aim of the study was to assess and compare the dimensions of QoL in the different stages of CKD patients and also to identify the factors affecting QoL.

\section{Data and methods}

\subsection{Study design and setting}

A cross sectional study was conducted among CKD patients for a period of 8 months from September 2017-April 2018. This study was conducted in the outpatient of department of Nephrology, Justice K.S. Hegde Charitable Hospital, Deralakatte, Mangaluru.

\subsection{Ethical issues}

Prior to the initiation of study ethical clearance was obtained from the Institution Ethics Committee (NGSMIPS/IEC/11/2017-18),

\footnotetext{
${ }^{*}$ Corresponding author. Department of Pharmacy Practice, NGSM Institute of Pharmaceutical Sciences, Nitte (Deemed to be University), Paneer, Deralakatte, Mangaluru, Karnataka, 575018, India.

E-mail address: udayvenkatmateti@gmail.com (U.V. Mateti).
} 
Table 1

Demographic characteristics of CKD patients.

\begin{tabular}{|c|c|c|c|c|c|c|c|}
\hline \multirow[t]{2}{*}{ Variables } & & & \multicolumn{4}{|l|}{ Stages of CKD } & \multirow{2}{*}{$\begin{array}{l}\text { All the CKD patients } \\
-(\mathrm{n}=210), \%\end{array}$} \\
\hline & & & CKD - $3(n=20), \%$ & $\begin{array}{l}\mathrm{CKD}-4(\mathrm{n}=21) \\
\%\end{array}$ & $\begin{array}{l}\text { CKD - } 5(n=47) \\
\%\end{array}$ & $\begin{array}{l}\text { CKD - 5D } \\
(n=122), \%\end{array}$ & \\
\hline \multirow[t]{4}{*}{ Age groups (Years) } & \multicolumn{2}{|c|}{$<35$} & $7(35 \%)$ & $2(9.52 \%)$ & $17(36.17 \%)$ & $13(10.65 \%)$ & $39(18.6 \%)$ \\
\hline & \multicolumn{2}{|c|}{$35-50$} & $2(10 \%)$ & $5(23.80 \%)$ & $14(29.78 \%)$ & $24(19.67 \%)$ & $45(21.42 \%)$ \\
\hline & \multicolumn{2}{|c|}{$51-65$} & $8(40 \%)$ & $9(42.85 \%)$ & $16(34.04 \%)$ & $58(47.54 \%)$ & $91(43.33 \%)$ \\
\hline & \multicolumn{2}{|c|}{$>65$} & $3(15 \%)$ & $5(23.80 \%)$ & - & $27(22.13 \%)$ & $35(16.7 \%)$ \\
\hline Age (Mean \pm SD) & & & $47.55 \pm 19.13)$ & $56.57 \pm 16.64$ & $41.65 \pm 13.12$ & $56.07 \pm 14.52$ & $52 \pm 16.04$ \\
\hline \multirow{2}{*}{ Gender } & \multicolumn{2}{|c|}{ Male } & $16(80 \%)$ & $18(85.71 \%)$ & $36(76.59 \%)$ & $96(78.68 \%)$ & 166(79.04\%) \\
\hline & \multicolumn{2}{|c|}{ Female } & $4(20 \%)$ & $3(14.28 \%)$ & $11(23.40 \%)$ & $26(21.31 \%)$ & $44(20.95 \%)$ \\
\hline \multirow[t]{2}{*}{ Domiciliary status } & \multicolumn{2}{|c|}{ Rural } & $17(85 \%)$ & $16(76.19 \%)$ & $26(55.31 \%)$ & $89(72.95 \%)$ & $148(70.50 \%)$ \\
\hline & \multicolumn{2}{|c|}{ Urban } & $3(15 \%)$ & $5(23.80 \%)$ & $21(44.68 \%)$ & $33(27.04 \%)$ & $62(29.50 \%)$ \\
\hline \multirow[t]{2}{*}{ Employment status } & \multicolumn{2}{|c|}{ Employed } & $8(40 \%)$ & $12(57.14 \%)$ & $26(55.31 \%)$ & $27(22.13 \%)$ & $73(34.80 \%)$ \\
\hline & \multicolumn{2}{|c|}{ Unemployed } & $12(60 \%)$ & $9(42.85 \%)$ & $21(44.68 \%)$ & $95(77.86 \%)$ & $137(65.20 \%)$ \\
\hline \multirow{3}{*}{ Marital status } & \multicolumn{2}{|c|}{ Married } & $14(70 \%)$ & $20(95.23 \%)$ & $36(76.59)$ & 109(89.34\%) & $179(85.23 \%)$ \\
\hline & \multicolumn{2}{|c|}{ Unmarried } & $5(25 \%)$ & $1(4.76 \%)$ & $11(23.40 \%)$ & $13(10.65 \%)$ & $30(14.28 \%)$ \\
\hline & \multicolumn{2}{|c|}{ Widow } & $1(5 \%)$ & - & - & - & $1(0.47)$ \\
\hline \multirow{4}{*}{ Educational background } & \multicolumn{2}{|c|}{ Illiterate } & $6(30 \%)$ & $4(19.04 \%)$ & $6(12.76 \%)$ & $65(53.27 \%)$ & $81(38.60 \%)$ \\
\hline & \multicolumn{2}{|c|}{ Primary } & $7(35 \%)$ & $3(14.28 \%)$ & $8(17.02 \%)$ & $24(19.67 \%)$ & $42(20.00 \%)$ \\
\hline & \multicolumn{2}{|c|}{ Secondary } & $5(25 \%)$ & $9(42.85 \%)$ & $16(34.04 \%)$ & $14(29.78 \%)$ & $44(21.00 \%)$ \\
\hline & \multicolumn{2}{|c|}{ Graduate } & $2(10 \%)$ & $5(25 \%)$ & $17(36.17 \%)$ & $19(40.42 \%)$ & $43(20.50 \%)$ \\
\hline \multirow[t]{4}{*}{ Body mass index (BMI) } & & t $(\leq 18.5)$ & - & - & $6(12.76 \%)$ & $112(91.80 \%)$ & $118(56.19 \%)$ \\
\hline & & $.5-24.9)$ & 19(95\%) & $19(90.47 \%)$ & $33(70.21 \%)$ & $7(5.73 \%)$ & $78(37.14 \%)$ \\
\hline & & $(25-29.9)$ & $1(5 \%)$ & $2(9.52 \%)$ & - & - & $3(1.42 \%)$ \\
\hline & & & - & - & $8(17.02 \%)$ & $3(2.45 \%)$ & $11(5.23 \%)$ \\
\hline BMI (Mean \pm SD) & & & $21.09 \pm 4.19$ & $21.28 \pm 4.19$ & $22.18 \pm 5.85$ & $17.52 \pm 4.63$ & $19.28 \pm 4.66$ \\
\hline Co-morbidities & HTN & Yes & $18(90 \%)$ & $17(80.95 \%)$ & $43(91.48 \%)$ & $111(19.98 \%)$ & $189(90 \%)$ \\
\hline & & No & $2(10 \%)$ & $4(19.04 \%)$ & $4(8.51 \%)$ & $11(9.01 \%)$ & $21(10 \%)$ \\
\hline & DM & Yes & $9(45 \%)$ & $17(80.95 \%)$ & $22(46.80 \%)$ & $59(48.36 \%)$ & $107(51 \%)$ \\
\hline & & No & $11(55 \%)$ & $4(19.04 \%)$ & $25(53.19 \%)$ & $63(51.63 \%)$ & $103(49 \%)$ \\
\hline & IHD & Yes & $3(15 \%)$ & $4(19.04 \%)$ & $3(6.38 \%)$ & $22(18.03 \%)$ & $32(15.20 \%)$ \\
\hline & & No & $17(85 \%)$ & $17(18.95 \%)$ & $44(93.61 \%)$ & $100(81.96 \%)$ & $178(84.80 \%)$ \\
\hline Number of medications per & $\leq 5$ & & $16(80 \%)$ & $4(19.04 \%)$ & $7(14.89 \%)$ & $12(9.83 \%)$ & $39(18.57 \%)$ \\
\hline prescription & $5-8$ & & $4(20 \%)$ & $14(66.66 \%)$ & $29(61.70 \%)$ & $82(67.21 \%)$ & $129(61.42 \%)$ \\
\hline & $9-11$ & & - & $3(14.28 \%)$ & $7(14.89 \%)$ & $18(14.75 \%)$ & $28(13.33 \%)$ \\
\hline & $\geq 11$ & & - & - & $4(8.51 \%)$ & $10(8.19 \%)$ & $14(6.66 \%)$ \\
\hline$($ Mean $\pm S D)$ & & & $4.65 \pm 2.41$ & $7.52 \pm 2.41$ & $7.53 \pm 2.47$ & $8.09 \pm 2.26$ & $7.580 \pm 2.41$ \\
\hline
\end{tabular}

BMI - Body Mass Index, HTN - Hypertension, DM - Diabetics Mellitus, IHD - Ischemic Heart Disease, SD- Standard Deviation, CKD- Chronic Kidney Disease.

Mangaluru, Karnataka, India. Patients were recruited after obtaining the informed consent from the patients.

\subsection{Study criteria}

The inclusion criterion of the study was Patients above 18 years age diagnosed with CKD stage 3-5 and patients undergoing maintenance haemodialysis (HD). Kidney transplantation (KT), peritoneal dialysis (PD), patients shifted from KT or PD to haemodialysis, pregnant and lactating women were excluded from the study.

\subsection{Data collection and QoL assessment}

Patients who met the inclusion criteria the demographic details include Age, gender, marital status, educational background, employment status, comorbidities, body mass index (BMI), social habits, domiciliary status, frequency of HD sessions per week and number of medications prescribed were collected from the medical records and patients. The patients QoL were assessed using the Euro-QoL-5D-5L (EQ-5D) and VAS questionnaires. ${ }^{7}$ Prior to the usage of validated versions of English, Kannada and Malayalam Euro-QoL-5D- 5L and VAS questionnaires the permission was obtained from the Euro QoL group. The EQ-5D-5L QoL questionnaire consists of 5 questions related to mobility, self-care, usual activities, pain or discomfort and anxiety or depression. The EQ-VAS measures the patient's self-rated health on a vertical scale. The VAS score ranged from 0 to 100 in which the endpoints are marked as 100 "good health" and 0 as "worst health". The EQ-5D index scores were calculated using the EQ-5D-5L Crosswalk
Index Value Calculator. $^{8}$

\subsection{Statistical analysis}

Categorical data are presented as frequency and percentage. Continuous variables are presented as mean and standard deviation. The association between the continuous variables (two groups) vs EQ$5 \mathrm{D}$ index; and VAS scores were assessed using independent sample $t$ test. The association between the continuous variables (more than two groups) vs EQ-5D index; and VAS scores were assessed using ANOVA test. The $\mathrm{p}$ value ${ }^{<} 0.05$ was considered as statistically significant. The data was analysed in the SPSS version 20.0.

\section{Results}

Among 210 patients, the majority of the patients enrolled in the study belong to CKD stage 5D (58.1\%), followed by stage $5(22.4 \%)$. The patients undergoing HD $(58.10 \%)$ outnumbered the non-dialysis (41.90\%) patients. The age wise distributions of the CKD patients were in the range from 19 to 85 years, among which the highest proportion of patients were observed in the age group between 51 and 65 years (43.33\%). The mean age of the study population was $52 \pm 16.04$. In gender wise distribution, male patients $166(79.04 \%)$ outnumbered the female patients 44 (20.95\%). Most of the patients were from rural $(n=148)$ area whereas remaining CKD patients were from urban area $(n=62)$. Overviewing the employment status, majority of patients were unemployed (65.20\%), which was most commonly observed in CKD 5D (77.86\%). Educational background varied in different patients 
Table 2

Domains of QoL in various stages of CKD.

\begin{tabular}{|c|c|c|c|c|c|c|}
\hline QoL Domains & & Stages of CKD & & & & All the CKD patients \\
\hline \multirow[t]{6}{*}{ Mobility } & Level & CKD - $3(n=20), \%$ & CKD $-4(n=21), \%$ & CKD - $5(n=47), \%$ & CKD - 5D $(n=122), \%$ & Number of patients $(n=210), \%$ \\
\hline & 1 & $19(95 \%)$ & $17(80.95 \%)$ & $37(78.72 \%)$ & $69(56.55 \%)$ & $142(67.60 \%)$ \\
\hline & 2 & $1(5.00 \%)$ & $4(19.04 \%)$ & $10(21.27 \%)$ & $42(34.42 \%)$ & $57(27.10 \%)$ \\
\hline & 3 & - & - & - & $3(2.45 \%)$ & $3(1.42 \%)$ \\
\hline & 4 & - & - & - & $6(4.91 \%)$ & $6(2.85 \%)$ \\
\hline & 5 & - & - & - & $2(1.63 \%)$ & $2(1.00 \%)$ \\
\hline \multirow[t]{5}{*}{ Self-care } & 1 & $20(100 \%)$ & $16(76.19 \%)$ & $32(68.08 \%)$ & $45(36.88 \%)$ & $113(53.80 \%)$ \\
\hline & 2 & - & $5(23.80 \%)$ & $14(29.78 \%)$ & $70(57.37 \%)$ & $89(42.40 \%)$ \\
\hline & 3 & - & - & $1(2.12 \%)$ & $5(4.09 \%)$ & $6(2.90 \%)$ \\
\hline & 4 & - & - & - & $1(0.81 \%)$ & $1(0.50 \%)$ \\
\hline & 5 & - & - & - & $1(0.81 \%)$ & $1(0.50 \%)$ \\
\hline \multirow[t]{5}{*}{ Usual Activities } & 1 & $11(55 \%)$ & $4(19.04 \%)$ & $14(29.78 \%)$ & $15(12.29 \%)$ & $44(21 \%)$ \\
\hline & 2 & $6(30 \%)$ & $10(47.61 \%)$ & $15(31.91 \%)$ & $47(38.52 \%)$ & $78(37.10 \%)$ \\
\hline & 3 & $3(15 \%)$ & $4(19.04 \%)$ & $11(23.40 \%)$ & $37(30.32 \%)$ & $55(26.20 \%)$ \\
\hline & 4 & - & $3(14.28 \%)$ & $7(14.89 \%)$ & $20(16.39 \%)$ & $30(14.30 \%)$ \\
\hline & 5 & - & - & - & $3(6.38 \%)$ & $3(1.40 \%)$ \\
\hline \multirow[t]{5}{*}{ Pain } & 1 & $10(50 \%)$ & $8(38.09 \%)$ & $15(31.91 \%)$ & $17(13.93 \%)$ & $50(23.80 \%)$ \\
\hline & 2 & $10(50 \%)$ & $10(47.61 \%)$ & $24(51.06 \%)$ & $48(39.34 \%)$ & $92(43.80 \%)$ \\
\hline & 3 & - & $3(14.28 \%)$ & $2(4.25 \%)$ & $36(29.50 \%)$ & $41(19.52 \%)$ \\
\hline & 4 & - & - & $6(12.76 \%)$ & $15(12.29 \%)$ & $21(10 \%)$ \\
\hline & 5 & - & - & - & $6(4.91 \%)$ & $6(2.85 \%)$ \\
\hline \multirow[t]{5}{*}{ Anxiety } & 1 & $13(65 \%)$ & $8(38.09 \%)$ & $17(36.17 \%)$ & $21(17.21 \%)$ & $59(28.09 \%)$ \\
\hline & 2 & $5(25 \%)$ & $10(47.61 \%)$ & $15(31.91 \%)$ & $57(46.72 \%)$ & $87(41.42 \%)$ \\
\hline & 3 & $2(10 \%)$ & $1(4.76 \%)$ & $11(23.40 \%)$ & $26(21.31 \%)$ & $40(19.04 \%)$ \\
\hline & 4 & - & $2(9.52 \%)$ & $4(8.41 \%)$ & $15(12.29 \%)$ & $21(10 \%)$ \\
\hline & 5 & - & - & - & $3(2.45 \%)$ & $3(1.42 \%)$ \\
\hline
\end{tabular}

QoL-Quality of Life, CKD- Chronic Kidney Disease.

among which (61.4\%) of them were literate which was most commonly observed in CKD 5D (65\%), followed by $21 \%$ of them had secondary education. Majority of CKD patients were underweight (56.19\%) and mean BMI of the study population was $19.28 \pm 4.66 \mathrm{~kg} / \mathrm{m}^{2}$. The most common co-morbidities were HTN (90\%) followed by DM $(51 \%)$ and others. Comparing the various stages of CKD patients, it was found that the majority of patients were alcoholic (29.50\%). Majority of patients were married $(85.23 \%)$, whereas $14.28 \%$ of patients were unmarried followed by $0.47 \%$ of widow. The mean number of medications per prescription was $7.58 \pm 2.41$. The demographic characteristics of patients are summarized in Table 1.

The most commonly affected QoL domains in the study populations were usual activities (79\%), pain (76.20\%) and anxiety and depression (71.91\%). The detailed QoL domains affected in patients are summarized in Table 2. The mean EQ-5D index scores of the CKD stage 3, 4, 5 and $5 \mathrm{D}$ patients were $0.77 \pm 0.09,0.67 \pm 0.10,0.62 \pm 0.12$ and $0.50 \pm 0.15$ and the mean VAS score for these stages were $74.10 \pm 7.68,66.52 \pm 10.90,66.45 \pm 8.80$ and $55.04 \pm 12.82$ respectively.

By correlating different stages of CKD with EQ - 5D Index scores it was found that QoL of CKD stage 3 patients had better than stage 5 ( $p-$ $0.000)$ and $5 D(p-0.000)$. QoL of CKD stage 4 had better QoL than CKD stage 5D ( $p-0.000)$. QoL of CKD stage 5 had better QoL than CKD 5D $(p-0.000)$. The CKD stage 5D had worse QoL compared to all other three stages of CKD (p-0.000). The association between the demographic characteristics and EQ-5D Index scores are summarized in Table 3. Correlation of different stages of CKD with VAS score it was found that QoL of CKD stage 3 is better than stage 5D (P - 0.000). QoL of CKD stage 4 had better QoL than CKD stage 5D (p - 0.000). QoL of CKD stage 5 had better QoL than CKD 5D ( $\mathrm{p}-0.000)$. CKD stage 5D had worse QoL compared to all other three stages of CKD (p-0.000).

The factors such as age, DM, BMI, education, unemployment, domiciliary status, duration of HD, number of medications had significant association with EQ-5D Index and VAS scores $(\mathrm{p}-0.000)$. The association between the demographic characteristics and VAS scores are summarized in Table 4.

\section{Discussion and conclusion}

EQ-5D was used in several studies to assess the QoL among chronic diseases patients. ${ }^{9}$ In the present study, EQ-5D was used to compare the QoL dimensions of different stages of CKD patients. Overall the QoL was better in patients with CKD stage 3-4, followed by stage 5 , and patients on haemodialysis. It was found that QoL was impaired in stage 5D compared to other stages ( $\mathrm{p}-0.000)$. Similar findings were found in the studies conducted by Pagel M et al., Eriksson E et al., reported that the QoL was impaired in stage 5D compared to other stages $(\mathrm{p}-0.000){ }^{10,11}$ Eriksson E et al., also reported the better EQ-5D index and VAS scores for the CKD stages 3-5 and 5D than the present study. ${ }^{11}$ Whereas in a study conducted by Kathib ST et al., reported comparatively less EQ-5D index and VAS scores and Sakthong P et al., reported the better EQ-5D index and VAS scores for the CKD-5D than present study. ${ }^{12,13}$

In the study, the most commonly affected domains among the study population were usual activities (79\%), pain (76.20\%) and anxiety and depression (71.91\%). The study conducted by Errikson E et al., reported that most commonly affected domains were pain (63.3\%) and anxiety/ depression (41.97\%). In an another study conducted by Saffari M et al., reported that mobility $(59.4 \%)$ was the most commonly affected domain followed by pain $(47.8 \%){ }^{11,14}$

In our study, most of the CKD patients were in the age group between 51 and 65 years (43.33\%) and the mean age of the study population was $52 \pm 16.04$. The EQ-5D index and VAS scores had strong association with age groups $(\mathrm{p}-0.000)$. The results were in correspondence with the study conducted by Zyoud SH et al., where the mean age of the study population was $53.3 \pm 16.2$. The study also reported that EQ-5D index ( $\mathrm{p}-0.010)$ and VAS scores $(\mathrm{p}-0.001)$ had the strong association with age. ${ }^{1}$ A study carried out by Pezeshki ML et al., reported that the mean age of the study population was $51.76 \pm 17.37$. No significant association with age was found with kidney disease component (KDC) score ${ }^{15}$

In our study, it was found that male patients 166 (79.04\%) outnumbered the female patients 44 (20.95\%). Gender had no significant association with EQ-5D score (p-0.712) and VAS score (p-0.633). Similar results were shown in a study carried out by Cruz M et al., 
Table 3

Analysis of Demographic characteristics vs. EQ - 5D Index scores.

\begin{tabular}{|c|c|c|c|c|c|}
\hline \multicolumn{3}{|l|}{ Variable } & $\begin{array}{l}\text { Frequency } \\
(\mathrm{n}=210)\end{array}$ & $\begin{array}{l}\text { EQ-5D index } \\
\text { score } \\
\text { Mean } \pm S D\end{array}$ & $\mathrm{p}$ value \\
\hline \multirow[t]{4}{*}{ Age } & \multicolumn{2}{|l|}{$<35$} & 39 & $0.76 \pm 0.07$ & 0.000 \\
\hline & \multicolumn{2}{|l|}{$35-50$} & 45 & $0.61 \pm 0.05$ & \\
\hline & \multicolumn{2}{|l|}{$51-65$} & 91 & $0.53 \pm 0.09$ & \\
\hline & \multicolumn{2}{|l|}{$>65$} & 35 & $0.38 \pm 0.20$ & \\
\hline \multirow[t]{2}{*}{ Gender } & \multicolumn{2}{|l|}{ Male } & 166 & $0.55 \pm 0.16$ & 0.712 \\
\hline & \multicolumn{2}{|c|}{ Female } & 44 & $0.60 \pm 0.15$ & \\
\hline \multirow[t]{4}{*}{ BMI } & \multicolumn{2}{|c|}{ Underweight } & 118 & $0.51 \pm 0.15$ & 0.000 \\
\hline & \multicolumn{2}{|c|}{ Normal } & 78 & $0.75 \pm 0.51$ & \\
\hline & \multicolumn{2}{|c|}{ Overweight } & 3 & $0.65 \pm 0.13$ & \\
\hline & \multicolumn{2}{|l|}{ Obese } & 11 & $0.50 \pm 0.11$ & \\
\hline \multirow{4}{*}{$\begin{array}{l}\text { Education } \\
\text { background }\end{array}$} & \multicolumn{2}{|c|}{ Illiterate } & 81 & $0.44 \pm 0.14$ & 0.000 \\
\hline & \multicolumn{2}{|c|}{ Primary } & 42 & $0.57 \pm 0.11$ & \\
\hline & \multicolumn{2}{|c|}{ Secondary } & 44 & $0.65 \pm 0.10$ & \\
\hline & \multicolumn{2}{|c|}{ Graduated } & 43 & $0.71 \pm 0.07$ & \\
\hline \multirow{2}{*}{$\begin{array}{c}\text { Employment } \\
\text { status }\end{array}$} & \multicolumn{2}{|c|}{ Employed } & 73 & $0.69 \pm 0.09$ & 0.000 \\
\hline & \multicolumn{2}{|c|}{ Unemployed } & 137 & $0.50 \pm 0.15$ & \\
\hline \multirow[t]{2}{*}{ Domiciliary status } & \multicolumn{2}{|c|}{ Rural } & 148 & $0.52 \pm 0.15$ & 0.000 \\
\hline & \multicolumn{2}{|l|}{ Urban } & 62 & $0.67 \pm 0.11$ & \\
\hline \multirow[t]{2}{*}{ Marital status } & \multirow{2}{*}{\multicolumn{2}{|c|}{$\begin{array}{l}\text { Married } \\
\text { Unmarried }\end{array}$}} & 179 & $0.54 \pm 0.15$ & 0.833 \\
\hline & & & 30 & $0.72 \pm 0.14$ & \\
\hline Smoking & Yes & & 37 & $0.51 \pm 0.20$ & 0.140 \\
\hline & No & & 173 & $0.58 \pm 0.15$ & \\
\hline Alcohol & Yes & & 62 & $0.55 \pm 0.16$ & 0.352 \\
\hline & No & & 148 & $0.57 \pm 0.16$ & \\
\hline No. of medications & $<5$ & & 39 & $0.65 \pm 0.17$ & 0.000 \\
\hline & $5-8$ & & 129 & $0.57 \pm 0.14$ & \\
\hline & $9-11$ & & 28 & $0.52 \pm 0.14$ & \\
\hline & $>11$ & & 14 & $0.39 \pm 0.22$ & \\
\hline Comorbidities & HTN & Yes & 189 & $0.56 \pm 0.16$ & 0.596 \\
\hline & & No & 21 & $0.56 \pm 0.16$ & \\
\hline & DM & Yes & 107 & $0.54 \pm 0.17$ & 0.185 \\
\hline & & No & 103 & $0.59 \pm 0.14$ & \\
\hline & IHD & Yes & 32 & $0.48 \pm 0.13$ & 0.430 \\
\hline & & No & 178 & $0.58 \pm 0.16$ & \\
\hline Stages of CKD & CKD - & & 20 & $0.77 \pm 0.09$ & 0.000 \\
\hline & CKD - & & 21 & $0.67 \pm 0.10$ & \\
\hline & CKD - & & 47 & $0.62 \pm 0.12$ & \\
\hline & CKD - & & 122 & $0.50 \pm 0.15$ & \\
\hline
\end{tabular}

BMI- Body Mass Index, HTN- Hypertension, DM- Diabetic Mellitus, IHDIschemic Heart Disease,CKD- Chronic Kidney Disease.

where male patients $108(56.5 \%)$ outnumbered the female patients 83 (43.45\%) respectively. Whereas Xu RH et al., reported that gender has strong association with EQ-5D score (p-0.001) ${ }^{16,17}$

The most common comorbidities reported in the study were HTN (90\%) and DM (51\%). The VAS score had significant association with DM (p-0.000). Similar results were shown in studies carried out by Mujais SK et al., and Manavalan M et al., where, the most common comorbidities were HTN and DM. Mujais SK et al., showed significant association between the QoL scores with HTN and DM, whereas, Manavalan M et al., showed that KDC score has no significant association with HTN and DM ${ }^{18,19}$

In the present study, most of the patients were underweight (56.19\%). VAS score and EQ - 5D score had significant association with BMI (p-0.000). These results are contradictory to the studies carried out by Zyoud SH et al., and Aggarwal HK et al., where, majority of the patients were at healthier levels. Zyoud SH et al., reported that BMI had significant association with EQ-5D score (p-0.047) whereas, Aggarwal HK et al., reported no significant association with BMI ${ }^{1,20}$

Majority of the patients were literates (61.4\%) and educational status had significant association with EQ-5D score and VAS score (p-0.000). These results were similar to the studies conducted by Manavalan $\mathrm{M}$ et al., Pezeshki ML et al., where, they reported that most of the patients were literates and educational status had significant association with KDC scores, p values 0.00 and 0.04 respectively ${ }^{15,19}$

Majority of the patients in our study were unemployed $(65.20 \%)$
Table 4

Analysis of Demographic characteristics vs. VAS scores.

\begin{tabular}{|c|c|c|c|c|c|}
\hline \multicolumn{3}{|l|}{ Variable } & $\begin{array}{l}\text { Frequency } \\
(\mathrm{n}=210)\end{array}$ & $\begin{array}{l}\text { VAS scores } \\
(\text { Mean } \pm S D)\end{array}$ & $\mathrm{p}$ value \\
\hline \multirow[t]{4}{*}{ Age } & \multicolumn{2}{|l|}{$<35$} & 39 & $76.38 \pm 4.14$ & 0.000 \\
\hline & \multicolumn{2}{|l|}{$35-50$} & 45 & $67.55 \pm 4.59$ & \\
\hline & \multicolumn{2}{|l|}{$51-65$} & 91 & $57.28 \pm 7.89$ & \\
\hline & \multicolumn{2}{|l|}{$>65$} & 35 & $42.42 \pm 12.20$ & \\
\hline \multirow[t]{2}{*}{ Gender } & \multicolumn{2}{|l|}{ Male } & 166 & $59.91 \pm 13.10$ & 0.633 \\
\hline & \multicolumn{2}{|l|}{ Female } & 44 & $62.81 \pm 13.70$ & \\
\hline \multirow[t]{4}{*}{ BMI } & \multicolumn{2}{|c|}{ Underweight } & 118 & $0.56 \pm 12.97$ & 0.000 \\
\hline & \multicolumn{2}{|c|}{ Normal } & 78 & $75 \pm 5$ & \\
\hline & \multicolumn{2}{|c|}{ Overweight } & 3 & $66.02 \pm 12.03$ & \\
\hline & \multicolumn{2}{|l|}{ Obese } & 11 & $56.27 \pm 10.56$ & \\
\hline \multirow{4}{*}{$\begin{array}{l}\text { Education } \\
\text { background }\end{array}$} & \multicolumn{2}{|c|}{ Illiterate } & 81 & $49.04 \pm 11.09$ & 0.000 \\
\hline & \multicolumn{2}{|c|}{ Primary } & 42 & $61.71 \pm 9.17$ & \\
\hline & \multicolumn{2}{|c|}{ Secondary } & 44 & $68.65 \pm 7.18$ & \\
\hline & \multicolumn{2}{|c|}{ Graduated } & 43 & $72.81 \pm 5$ & \\
\hline \multirow{2}{*}{$\begin{array}{c}\text { Employment } \\
\text { status }\end{array}$} & \multicolumn{2}{|c|}{ Employed } & 73 & $70.54 \pm 6.84$ & 0.000 \\
\hline & \multicolumn{2}{|c|}{ Unemployed } & 137 & $55.20 \pm 12.76$ & \\
\hline \multirow{2}{*}{$\begin{array}{c}\text { Domiciliary } \\
\text { status }\end{array}$} & \multicolumn{2}{|c|}{ Rural } & 148 & $56.46 \pm 12.83$ & 0.000 \\
\hline & \multicolumn{2}{|l|}{ urban } & 62 & $70.32 \pm 8.19$ & \\
\hline \multirow[t]{2}{*}{ Marital status } & \multicolumn{2}{|c|}{ Married } & 179 & $58.28 \pm 12.51$ & 0.000 \\
\hline & Unmar & & 30 & $73.36 \pm 9.25$ & \\
\hline Smoking & Yes & & 37 & $57.35 \pm 15.16$ & 0.156 \\
\hline & No & & 173 & $61.24 \pm 12.75$ & \\
\hline Alcohol & Yes & & 62 & $60.50 \pm 12.35$ & 0.391 \\
\hline & No & & 148 & $60.58 \pm 13.65$ & \\
\hline No. of & $<5$ & & 39 & $65.41 \pm 14.29$ & 0.000 \\
\hline medications & $5-8$ & & 129 & $61.30 \pm 11.92$ & \\
\hline & $9-11$ & & 28 & $56.50 \pm 13.20$ & \\
\hline & $>11$ & & 14 & $48.28 \pm 13.74$ & \\
\hline Comorbidities & HTN & Yes & 189 & $60.66 \pm 12.89$ & 0.771 \\
\hline & & No & 21 & $59.57 \pm 16.48$ & \\
\hline & DM & Yes & 107 & $57.79 \pm 40$ & 0.002 \\
\hline & & No & 103 & $63.42 \pm 11.81$ & \\
\hline & IHD & Yes & 32 & $51.78 \pm 14.01$ & 0.224 \\
\hline & & No & 178 & $62.13 \pm 12.51$ & \\
\hline Stages of CKD & CKD - & & 20 & $74.10 \pm 7.68$ & 0.000 \\
\hline & CKD - & & 21 & $66.52 \pm 10.90$ & \\
\hline & CKD - & & 47 & $66.45 \pm 8.80$ & \\
\hline & CKD - & & 122 & $55.04 \pm 12.82$ & \\
\hline
\end{tabular}

BMI- Body Mass Index, HTN- Hypertension, DM- Diabetic Mellitus, IHDIschemic Heart Disease, CKD- Chronic Kidney Disease.

and the employment status showed significant association with EQ-5D score $(\mathrm{p}-0.000)$ but not with VAS score. This result is similar to the studies conducted by Kathib ST et al., Joshi U et al., and Pezeski ML et al., where more number of unemployed patients was reported and employment status had significant association with EQ-5D score ( $\mathrm{p}$ 0.001), WHO-QoL-BREF ( $\mathrm{p}$ - 0.04), (KDC) scores ( $\mathrm{p}$ - 0.02) respectively. Most of their patients were unemployed or stopped working due to their disease condition. ${ }^{12,15,21}$

In the present study, most of the patients were in rural areas $(70.50 \%)$ and had strong association with EQ-5D score ( $p-0.000)$. These results were in correspondence with the study carried out by Zyoud SH et al., where, higher number of patients were in rural areas $(60.3 \%)$ and showed significant association with EQ-5D score ( $p$ 0.004). A study carried out by Saffari $\mathrm{M}$ et al., reported that more patients were in urban areas $(94.2 \%)$ which is in contrast to the study results, but showed significant association with EQ-5D score (p 0.001). ${ }^{1,14}$

The mean number of medications prescribed per patient was $7.58 \pm 2.41$. The number of medications had significant association with EQ-5D index and VAS scores $(\mathrm{p}-0.000)$. These results are in contrast to the study conducted by Zyoud SH et al., where, mean number of medications was $6.5 \pm 2.8$ whereas, number of medications had strong association with EQ-5D index scores ( $\mathrm{p}-0.010)$ and VAS score (p - 0.042). ${ }^{1}$ The sample size of the study was small because the study duration was only 8 months and the cross-sectional study is difficult to interpret the association between the cause and effect were the 
limitations of the study.

Majority of the patients were in the age group 51-65 years (43.33\%). The mean age of study population was $52 \pm 16.04$. The most commonly affected domains were Usual Activities (79\%), Pain (76.20\%) and Anxiety/Depression (71.91\%). Factors such as age (> 65 yrs), BMI (Underweight and Obese), educational background (Illiterate), employment (Unemployed), domiciliary status (Rural), number of medications ( $>11$ ) had significant association with EQ-5D index and VAS scores ( $\mathrm{p}-0.000)$. It was found that QoL was impaired in stage 5D compared to other stages (p-0.000).

\section{Funding}

No funding of any kind was granted for carrying out this study.

\section{Authors' contribution}

UVM and PS conceptualized the study and analysed the data. MP, NS and MLP interpreted the results. MP, NS and MLP wrote the final draft. All the authors read and approved the final draft.

\section{Declaration of competing interest}

None.

\section{References}

1. Zyoud SH, Daraghmeh DN, Mezyed DO, et al. Factors affecting Quality of Life in patients on haemodialysis: a cross sectional study from Palestine. BMC Nephrol. 2016;17(44):1-12.

2. Kefale B, Alebachew M, adesse Y, Engidawork E. Quality of life and its predictors among patients with chronic kidney disease: a hospital-based cross sectional study. PloS One. 2019 Feb 27;14(2):e0212184.

3. Singh NP, Ingle GK, Saini VK, et al. Prevalence of low glomerular filtration rate, proteinuria and associated risk factors in North India using Cockcroft-Gault and Modification of Diet in Renal Disease equation: an observational, cross-sectional study. BMC Nephrol. 2009;10:4.

4. Jha $\mathrm{V}$, Wang $\mathrm{AY}$, Wang $\mathrm{H}$. The impact of CKD identification in large countries: the burden of illness. Nephrol Dial Transplant. 2012;27(3):iii32-38.

5. Perlman RL, Finkelstein FO, Liu L, et al. Quality of life in chronic kidney disease (CKD): a cross sectional Analysis in the renal research institute - CKD study. Am J Kidney Dis. 2005;45(4):658-666.

6. Awuah KT, Finkelstein SH, Finkelstein FO. Quality of life of chronic kidney disease patients in developing countries. Kidney Int Suppl. 2013;3(2):227.

7. Brooks R. EuroQol: the current state of play. Health Pol. 1996;37(1):53-72.

8. Van Hout B, Janssen MF, Feng YS, et al. Interim scoring for the EQ-5D-5L: mapping the EQ-5D-5L to EQ-5D-3L value sets. Value Health. 2012;15(5):708-715.

9. Tian F, Gao JM, Guo HT, Lian Z. An introduction to the studies and applications of EQ-5Q. Health Econ Res. 2007;9:42-44.

10. Pagels AA, Soderkvist BK, Medin C, Hylnder B, Heiwe S. Health related quality of life in different stages of CKD and at initiation of dialysis treatment. Health Qual Life Outcome. 2012;10(71):1-11.

11. Errikson D, Karlson L, Eklundo O, et al. HRQoL across all stages of autosomal dominant polycystic kidney disease. Nephrol Dial Transplant. 2017;32(12):2106-2111.

12. Khatib ST, Hemadneh MK, Hasan SA, Khazneh E, Zyoud SH. QoL in HD diabetic patients: a multicentre cross sectional study from Palestine. BMC Nephrol. 2018;19(49):1-9.

13. Sakthong P, Kasemsup V. Health utility measured with EQ-5D in Thai patients undergoing PD. Value Health. 2012;15(1 Suppl):S79-S84.

14. Saffari M, Pakpoor AH, Naderi MK, et al. Quality of life in hemodialysis patients. Nephrology. 2013;18:269-275.

15. Pezeshki LM, Rostami Z. Contributing factors in health-related quality of life assessment of ESRD patients: a single centre study. Int J Nephrol Urol. 2009;1(2):129-136.

16. Cruz MC, Andrade C, Urrutia M, Draibe S, Nogueira-Martins LA, Sesso Rde C. Quality of life in patients with chronic kidney disease. Clinics (Sao Paulo). 2011;66(6):991-995.

17. Xu RH, Cheung AW, Wong EL. Examining the health-related quality of life using EQ5D-5L in patients with four kinds of chronic diseases from specialist outpatient clinics in Hong Kong SAR, China. Patient Prefer Adherence. 2017;11:1565-1572.

18. Mujais SK, Story K, Brouillette J, et al. Health - related quality of life in CKD patients: correlates and evolution over time. Clin J Am Soc Nephrol. 2009;4(8):1293-1301.

19. Manavalan M, Majumdar A, Kumar KT, Priyamvada PS. Assessment of HRQoL in CKD patients. Indian J Nephrol. 2017;27(1):37-43.

20. Aggarwal HK, Jain D, Pawar S, Yadav RK. Health related quality of life in different stages of CKD. QJM. 2016;109(11):711-716.

21. Joshi VD. Assessment of Quality of life in patients with ESRD. World J Nephrol. 2014;3(4):308-316. 